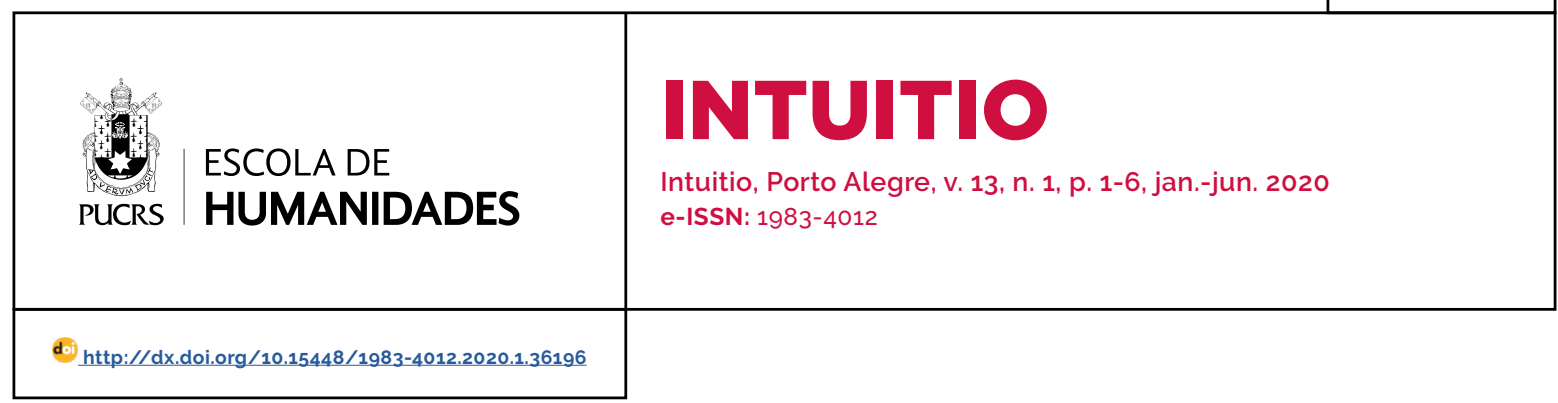

SEÇÃO: TRADUÇÃO

\title{
Manifesto por uma filosofia pública ${ }^{1}$
}

Manifesto for public philosophy

\section{Alysson Augusto dos Santos Souza ${ }^{2}$ orcid.org/0000-0002-9830-7056 alysson.souza@edu.pucrs.br}

Recebido em: 28 out. 2019. Aprovado em: 31 jan. 2020. Publicado em: 27 jul. 2020.

\section{(c) (i)}

Artigo está licenciado sob forma de uma licença Creative Commons Atribuição 4.0 Internacional.
Resumo: Produzir filosofia voltada ao engajamento público é uma tarefa dificil, pois existem barreiras pessoais e acadêmicas a serem superadas. Os filósofos, geralmente, não recebem incentivos institucionais suficientes para irem além da pesquisa e das palestras voltadas a seus pares acadêmicos, e isso tem criado uma cisão entre o mundo acadêmico qualificado e o mundo não acadêmico, havendo aí um vácuo de influência intelectual filosófica sendo preenchido por pessoas não capacitadas. Não se trata de forçar a academia a efetivamente produzir uma filosofia mais popular e atraente para as grandes massas, mas de torná-la mais caridosa e receptiva a iniciativas que vão nesse sentido, inclusive profissionalizando-as. O texto traduzido a seguir, do filósofo C. Thi Nguyen, propõe algumas sugestões práticas que podem levar à construção de uma filosofia pública mais atraente e institucionalmente valiosa. Com esse olhar mais atento ao fazer filosófico, acredita-se que a superação de muitas barreiras de entrada para novos filósofos será facilitada, e a filosofia ganhará nova relevância pública. Palavras-chave: Filosofia pública. Divulgação filosófica. Filosofia popular.

Abstract: Producing an engaged and public oriented philosophy is a difficult task as there are personal and academic barriers to overcome. Philosophers generally do not receive sufficient institutional incentives to go beyond research and lectures aimed at their academic peers, and this has created a split between the qualified academic world and the non-academic world, where there is a vacuum of philosophical intellectual influence being filled by untrained people. It is not a matter of forcing the academy to effectively produce a more popular and appealing philosophy for the masses, but of making it more charitable and responsive to initiatives that are in that direction, including professionalizing them. The following translated text from philosopher $\mathrm{C}$. Thi Nguyen proposes some practical suggestions that may lead to the construction of a more attractive and institutionally valuable public philosophy. With this more attentive look when doing philosophical work, it is believed that overcoming many barriers to entry for new philosophers will be facilitated, and philosophy will gain new public relevance. Keywords: Public philosophy. Philosophical disclosure. Popular philosophy.

\section{Nota do tradutor}

Quem é C. Thi Nguyen? Ele é professor de filosofia na Utah Valley University e busca, em suas pesquisas, compreender como estruturas sociais projetadas - tais como jogos, câmaras de eco, burocracias - podem mudar a maneira como raciocinamos, valorizamos e agimos. Seus esforços na comunicação de ideias o levaram a defender que é papel do filósofo apoiar a filosofia pública, tanto individual quanto institucionalmente. Isso

\footnotetext{
1 Nota do tradutor: O presente texto, de autoria do filósofo C. Thi Nguyen, da Universidade de Utah Valley, foi originalmente publicado em inglês na Daily Nous Magazine, em 1. de julho de 2019, sob o título "Manifesto for Public Philosophy". Disponivel em: http://dailynous. com/2019/07/01/manifesto-public-philosophy-guest-post-c-thi-nguyen. Acesso em: 21 maio 2020.

2 Pontifícia Universidade Católica do Rio Grande do Sul (Pucrs), Porto Alegre, RS, Brasil.
} 
o guiou a escrever o texto (Manifesto for Public Philosophy), que veremos traduzido a seguir. Mais informações sobre o trabalho de Nguyen podem ser conferidas em seu site pessoal. ${ }^{3}$

\section{Manifesto por uma filosofia pública}

Um estudante me disse: o problema hoje em dia é que, se você não tem nenhum treinamento e está navegando online à procura de uma filosofia que seja fácil de compreender, nove entre dez das coisas que você encontrar serão da hate web. 4 Elas são propaganda, e não sementes de reflexão crítica. O que precisamos, se é que vamos lutar contra isso, é produzir filosofia de forma pública e em grande volume.

Recentemente eu passei algumas semanas em um workshop filosófico voltado à popularização da filosofia, e fiquei convencido de que a maioria de nós tem uma visão incrivelmente estreita quanto ao que uma filosofia popular ${ }^{5}$ poderia ser. Por exemplo: eu tendia a pensar que a filosofia popular era algo como um editorial em jornais e artigos no The Atlantic, e coisas assim. Mas há muito mais. Pessoas como ContraPoints ${ }^{6}$ e Wireless Philosophy ${ }^{7}$ estão fazendo filosofia no YouTube, alcançando um mundo muito mais amplo. Temos alguns podcasters, como Barry Lam e seu extraordinário podcast Hi Phi Nation. ${ }^{8}$ O pessoal do Ethics Bow ${ }^{9}$ está levando seu projeto às escolas secundárias, e mesmo às prisões. Existem fóruns de discussão pública, palestras públicas, programas de filosofia para crianças. Isso é exatamente o que precisamos - mas precisamos de muito mais disso. Precisamos preencher as ondas de rádio com as coisas boas, em todos os formatos: colunas e editoriais, posts de blogs, vídeos no YouTube, podcasts, artigos longos, palestras, fóruns, tweets e muito mais. A boa filosofia precisa estar em todos os lugares, acessivel a todos os niveis, a qualquer um que possa estar interessado. Precisamos inundar o mundo com portais de todas as formas e tamanhos.

Mas há muitas barreiras à entrada. Primeiro de tudo, os incentivos disciplinares não apoiam a popularização da filosofia. Para a maioria de nós, escrever artigos de opinião e criar vídeos no YouTube não ajuda você a conseguir um emprego, obter estabilidade ou ser promovido. Mas é pior que isso. Nossa disciplina resiste ativamente à popularização da filosofia.

Eu não estou dizendo que todo mundo precisa criar filosofia pública. Porém, acho que todos deveriam apoiar isso e estamos muito longe de realmente contar com esse amplo apoio. Deixe-me focar nas coisas escritas um pouco, porque é com o que estou mais familiarizado. Eu tenho conversado com várias pessoas que escreveram filosofia pública, e eu continuo ouvindo a mesma coisa. Se você voltar seus esforços para a popularização da filosofia, outros filósofos o atacarão por você ter sido simplista demais. Eles serão excessivamente críticos aos seus esforços. Certamente, muitas pessoas são apoiadoras e gratas e conseguem entender o que você está tentando fazer. Contudo, outras pessoas olham para uma filosofia popular, e o que elas veem é um trabalho de baixa qualidade pelos padrões acadêmicos. E elas ignoram todo o trabalho que foi feito para torná-la pública - para tornar a escrita clara e adorável, e talvez até um pouco divertida.

Escrever um pouco de filosofia popular exige um esforço absurdo. Se você foi profissionalizado, então você provavelmente terá que lutar contra

\footnotetext{
3 Disponivel em: https://objectionable.net/public-philosophy. Acesso em: 19 maio 2020.

4 Nota do tradutor: Literalmente "rede do ódio", referindo-se ao comportamento abusivo com que muitos internautas atuam nas redes sociais e espaços virtuais de convívio.

5 Nota do tradutor: os termos "filosofia pública", "filosofia popular", "popularização filosófica" e "divulgação filosófica" são utilizados para designar o mesmo desafio comentado pelo autor: a facilitação do acesso à filosofia por parte do grande público.

6 Canal no YouTube da criadora Natalie Wynn, cujos videos exploram temas como política, gênero, raça e filosofia. Disponível em: https://youtube.com/ContraPoints. Acesso em: 17 ago. 2019.

7 "Filosofia sem fio" ou "Wi-Phi" é um site de filosofia de acesso aberto que visa "introduzir as pessoas à prática da filosofia, fazendo vídeos que estão disponiveis gratuitamente de uma forma que é divertida". Disponivel em: https://youtube.com/WirelessPhilosophy Acesso em: 17 ago. 2019.

8 "Nação Hi-Phi" dirigido por Barry Lam que é ex-aluno da UC Irvine e ex-diretor de programa e gerente geral da KUCl 88.9FM. Doutor em filosofia pela Princeton University, Barry é Professor Associado de Filosofia na Vassar College. A Nação Hi-Phi foi aclamada pela crítica no Guardian, Huffington Post. Disponivel em: https://hiphination.org. Acesso em: 31 jan. 2020.

9 O Intercollegiate Ethics Bowl é uma atividade extracurricular em que duas equipes de estudantes debatem casos de macro e microescala. Criado em 1993 no Instituto de Tecnologia de Illinois, o Ethics Bowl tem crescido constantemente ao longo dos anos.
} 
todos os instintos que foram programados em você, durante sua longa viagem para ser moldado como um Bom Filósofo Profissional. Você tem que ser grande, você tem que esboçar livremente, você tem que apressar as distinções. Você tem que alcançar, duramente, aquelas cristalizações vigorosas. Você tem que se preocupar com a elegância. Você precisa desenvolver uma ideia profunda em 1000 palavras, 800 palavras, ou em um único maldito tweet. E para fazer isso, você precisa simplificar. Você está constantemente lutando uma guerra entre precisão e compressão, e sacrifícios precisam ser feitos. Como disse Rima Basu (no Twitter), fazer filosofia popular é sobre começar uma conversa.

Aqui está uma coisa que nossa comunidade poderia fazer sobre isso: poderíamos entender tudo isso. E muitas pessoas na profissão são, de fato, profundamente simpáticas. Eu deveria deixar absolutamente claro: escrever filosofia pública tem sido profundamente recompensador para mim. Talvez seja a melhor parte do meu trabalho. Filósofos e não filósofos expressaram sua gratidão e apoio pela minha disponibilização de ideias, por eu ter escrito coisas que são ensináveis a estudantes iniciantes. Mas outras pessoas na profissão estão dispostas a tratar a sua escrita popular como um alvo fácil no qual jogar algumas bombas filosóficas. E a perspectiva desse tipo de hostilidade pode criar uma barreira à entrada, especialmente para os membros mais jovens da profissão.

Então, aqui estão minhas sugestões para o que poderiamos fazer a fim de ajudar uns aos outros e para ajudar a filosofia a dar à luz a uma face pública maior e melhor.

\section{Seja caridoso}

Reconheça uma peça de filosofia popular por aquilo que ela é. Reconheça que o autor provavelmente não falhou de alguma forma idiota, mas provavelmente está sob enormes exigências para esclarecer, simplificar e compactar.

Isso não significa que você não deveria responder. Mas responda no nivel apropriado. A questão, ao responder a uma peça de filosofia pública, não é marcar pontos como se estivesse refutando um trabalho acadêmico. É demonstrar em público as qualidades de uma boa conversação critica.

Então, lance suas respostas a pedaços de filosofia popular no nivel adequado. Aqui está uma heuristica: imagine que você está fazendo uma discussão demonstrativa com outro filósofo em frente a uma aula introdutória. Você não o advertiria por ignorar os detalhes técnicos. Você entenderia que tudo estava em sintonia com o nivel de introdução, e você cooperaria em fazer movimentos filosóficos na dose certa. Você executaria a filosofia de uma maneira muito particular e pedagogicamente orientada, ao invés de simplesmente ir com tudo ao modo de massacre e refutação crítica.

E reconheça a diversidade de propósitos com a popularização filosófica. Amy Olberding ${ }^{10}$ explicou-me desta maneira: a filosofia pública não é apenas sobre lançar argumentos. Também pode ser sobre semear a incerteza, criar ambiguidade, complicar as coisas ou simplesmente deixar as pessoas empolgadas para pensar nas coisas. Estamos frequentemente presos ao modo de ver tudo como se fosse um argumento. Mas há tantas outras formas de demonstração pública de promulgar os valores da investigação crítica. Precisamos reconhecer que a filosofia pública é uma fera diferente, muitas vezes com objetivos muito distintos.

\section{Seja apoiador}

Definitivamente, seja um apoiador emocional, mas também apoie a prática pública. Compartilhar, retuitar, postar. As outras partes das humanidades são muito melhores nesse tipo de coisa do que nós. Os sociólogos, os psicólogos sociais: eles retuitam e compartilham uns com os outros constantemente. E eles fazem isso mesmo se não concordarem com todo o conteúdo especialmente quando se trata de qualquer peça publicamente orientada. Reunindo todos os seguidores de cada acadêmico, esses conteúdos

10 Professora de Ética e Filosofia Chinesa no Departamento de Filosofia da Universidade de Oklahoma. Recentemente publicou o livro The Wrong of Rudeness, literalmente "O erro da rudeza". 
escalam o algoritmo do Twitter e são vistos por mais e mais pessoas fora de sua disciplina. Os filósofos simplesmente não fazem isso. E nós poderiamos, e seria fácil.

E se você está preocupado que alguém possa te advertir por postar algo que possa estar errado, ou que você possa estar sendo interpretado como se estivesse endossando um ponto de vista, há todo um tipo de linguagem padrão que você pode usar para afastar isso. "Aqui está um novo trabalho interessante de..."

\section{Experimente novos formatos}

É tão fácil ficar preso na mentalidade de escrever e palestrar, e fazer toda a sua filosofia pública nesse molde: ensaios públicos e palestras públicas. Mas há muitos outros formatos que poderíamos usar, especialmente se nosso objetivo é destacar a metodologia e a mentalidade da filosofia: Youtube; Podcasts; Ethics Bowls; Conversas abertas casuais de fim de noite. Ian Olasov ${ }^{11}$ montou estandes em mercados de agricultores, festas de rua, e lojas de artigos domésticos, rotulados como "Pergunte a um Filósofo", estocando esses estandes com alguns filósofos locais e deixando qualquer um conversar com eles sobre qualquer coisa. Diversos filósofos que conheço estão envolvendo seus alunos com a divulgação filosófica, com tarefas que resultam em uma filosofia online realmente ao vivo: posts em blogs, conversas no Reddit, tweets e muito mais.

Aqui está uma ideia: por que os filósofos não fazem mais entrevistas? Refiro-me a filósofos fazendo perguntas, especialmente de não filósofos, e publicando entrevistas de perguntas e respostas em estilo jornalístico. Poderiamos estar entrevistando artistas, políticos, urbanistas, médicos, ativistas, agricultores, obras sociais e muito mais. Afinal, os filósofos não são apenas bons em argumentar - somos bons em fazer perguntas. Questões profundas e interessantes. Há certa ironia no fato de que os filósofos valorizam o questionamento de mente aberta, mas geralmente fazem isso em público apenas quando falam e escrevem para outras pessoas. Se nosso objetivo é expor as raizes da reflexão critica e da investigação, uma das maneiras pelas quais poderiamos fazê-lo é exibindo, em público, uma atitude genuinamente aberta, questionadora e exploratória.

Isso é o que podemos fazer como indivíduos. Mas também acho que há algumas mudanças sistemáticas que podemos realizar. E aqui faço referência a vocês com algum tipo de poder institucional.

\section{Universidades e departamentos: recompensem o engajamento público}

Isso significa, entre outras coisas, escrever sobre vaga e promoção de trabalho e adotar critérios de linguagem relativos a engajamento público. Alguns lugares, como o Reino Unido, começaram a fazer esse tipo de coisa. A infraestrutura acadêmica nos EUA, por outro lado, está devendo radicalmente quando a esse ponto. Mas fazer filosofia popular de forma certa consome tempo, energia fisica e espiritual. Neste momento, para a maioria de nós, se você está procurando um emprego ou uma posição, então escrever filosofia pública não o ajudará em nada. Da perspectiva da instituição: é apenas uma distração da única coisa que realmente importa, que é a publicação de artigos. Se realmente queremos apoiar e encorajar a filosofia pública, precisamos fazer com que ela valha algo em termos de moeda institucional. E algumas de nossas organizações estão começando a exigir exatamente isso ${ }^{12}$ - embora eu ainda não tenha visto muitas mudanças reais nesse sentido.

Mas podemos pensar ainda mais longe. $O$ campo da história, por exemplo, tem pessoas - mesmo em universidades sofisticadas - cuja principal função é escrever obras publicamente acessiveis de história (Eles até têm uma organização profissional, o Conselho Nacional de

\footnotetext{
11 Filósofo formado na Universidade de New York e ligado ao projeto Wireless Philosophy.

12 Nota do tradutor: o autor faz alusão ao apoio institucional da American Philosophical Association (APA) pela adoção de critérios favoráveis à filosofia pública em departamentos de filosofia. Conferir WEINBERG, Justin. APA Issues Statement On Valuing Public Philosophy. Dailynous, 18 maio 2017. Disponivel em: http://dailynous.com/2017/05/18/apa-issues-statement-valuing-public-philosophy. Acesso em: 18 ago. 2019.
} 
História Pública, dedicada a essa causa). E quando você tem especialistas em trabalho público, esses especialistas levam os estudantes e os treinam nas formas de engajamento público. Assim, toda aquela habilidade e sabedoria ganhas arduamente para fazer um bom engajamento público não se perde entre as gerações. Precisamos fazer isso também. Porque escrever filosofia para o público é uma habilidade peculiar e incrivelmente difícil, e agora a maioria de nós que está tentando fazer isso está tendo que reinventar a roda, por conta própria.

Aqui está uma sugestão para um primeiro passo: poderíamos começar a prática de tornar a "Filosofia Pública" uma área de competência ou especialização. Se realmente nos importássemos com esse tipo de coisa, poderiamos criar empregos para pessoas que fazem, digamos, ética ou qualquer outra coisa, mas também fazem filosofia pública. E essas pessoas poderiam dar aulas ocasionais sobre essa habilidade muito especial. Isso ajudaria muito a preservar e promulgar as habilidades da filosofia pública conquistadas com tanto esforço. E, ao mesmo tempo, podemos disponibilizar mais e melhores recursos online. Existem alguns recursos disponiveis online, ${ }^{13}$ mas isso é apenas o começo. Nós precisamos de muito mais.

E nós precisamos ir além dos limites da nossa profissão. Recentemente, participei de um workshop sobre redação pública para filósofos, dirigido por um jornalista e editor profissional. Eles arrancaram o inferno dos papéis e apontaram todos os pedaços alienantes que fediam ao insiderismo ${ }^{14}$ acadêmico. Então, para as pessoas segurando os cordões: financie esse tipo de coisa! Se nós, como filósofos, realmente nos importamos com a filosofia pública, isso não pode ser apenas um espetáculo secundário. É preciso que seja sistematicamente apoiado. Precisamos de filosofia pública para contar; precisamos lançar recursos para isso; precisamos treinar pessoas para isso.

\section{Periódicos: deixem claro que as apresentações de trabalho voltadas ao público não impedem sua posterior publicação acadêmica}

Este é um ponto pequeno, mas é representativo do tipo de pequenas correções institucionais que precisaremos fazer em todo o lugar.

Eu tenho sido um editor de um blog de filosofia da arte por um tempo, e a preocupação que eu ouço de meus colaboradores é: "será que escrever uma versão curta de blog sobre esse tópico põe em risco minhas chances de publicar a versão completa?" Infelizmente, não posso realmente dar uma resposta às pessoas, porque não há um padrão. Queremos que os filósofos possam blogar sobre suas ideias ou escrever colunas em jornais sem se preocuparem com a perda de suas publicações acadêmicas. Isso é especialmente importante para aqueles de nós que trabalham em questões como a natureza da injustiça estrutural, o racismo, a misoginia, a desinformação e a polarização política. Porque se a filosofia realmente importa, então provavelmente não deveriamos fazer os filósofos esperarem, por exemplo, dois anos para que seus artigos acadêmicos sejam publicados antes que eles possam escrever essas colunas.

Sugiro que os editores de periódicos adotem um padrão coletivo simples. Que tal algo como: "A publicação ou apresentação de um argumento em um local público não impede sua publicação neste periódico, desde que a versão publicada anteriormente contenha menos de um quarto do conteúdo da versão submetida para publicação em nossa plataforma (situações em que o limite de um quarto é excedido podem ser negociadas caso a caso)". Dessa forma, um artigo padrão de 1000 palavras não colocará em risco a publicação de um artigo de periódico padrão. E eu apostaria que, se alguns periódicos importantes adotassem tal padrão, o resto seguiria o precedente.

Para falar sem rodeios: o mundo está em crise.

13 Confira o site Public Philosophy Network, rede que promove a filosofia engajada em questões públicas. Disponivel em: http://publicphilosophynetwork.ning.com. Acesso em: 18 ago. 2019

${ }_{14}$ Nota do tradutor: insiderismo é claramente um neologismo para dar conta da expressão insiderism que se refere àquelas condutas linguísticas conhecidas somente pelos pares de um grupo especifico, que no caso do texto aqui poderia ser próximo do que chamamos de academicismo. 
É guerra, a alma da humanidade está em jogo, e a disciplina que esteve em treinamento isolado por 2000 anos até este exato momento está ocupada demais apontando erros minúsculos da técnica de um e de outro para realmente se juntar à luta. Estamos ocupados dando desnecessária atenção a trabalhos, publicações, o processo de revisão e todas as outras minúcias da academia. Nossa disciplina precisa dar um passo à frente. Precisamos fazer filosofia no mundo. Precisamos mudar nossas normas mofadas para apoiar esse engajamento público. Ou nos tornaremos irrelevantes por nossa própria inação.

\section{Referências}

APPE IEB. Intercollegiate Ethics Bowl. Disponivel em: https://appe-ethics.org/ethics-bowl/. Acesso em: 31 jan. 2020.

CONTRAPOINTS. Dir. Natalie Wynn. Canal do YouTube. com. Disponivel em: https://youtube.com/ContraPoints/. Acesso em: 17 ago. 2019.

HI PHI NATION. Dir. Barry Lam. Podcast. Disponivel em: https://hiphination.org/. Acesso em: 31 jan. 2020.

NGUYEN, C. Thi. Manifesto for Public Philosophy. Daily Nous Magazine, $1^{\circ}$ jul. 2019, sob o título. Disponivel em: http://dailynous.com/2019/07/01/manifesto-public-philosophy-guest-post-c-thi-nguyen/. Acesso em: 17 ago. 2019.

PUBLIC PHILOSOPHY NETWORK. Site na internet. Disponivel em: http://publicphilosophynetwork.ning. com. Acesso em: 31 jan. 2020.

WEINBERG, Justin. APA Issues Statement On Valuing Public Philosophy. In: Dailynous, 18 maio 2017. Disponivel em: http://dailynous.com/2017/05/18/apa-issues-statement-valuing-public-philosophy/. Acesso em: 18 ago. 2019.

WIRELESS PHILOSOPHY. Canal do YouTube.com. Disponivel em: https://youtube.com/WirelessPhilosophy. Acesso em: 17 ago. 2019.

\section{Alysson Augusto dos Santos Souza}

Mestrando em Filosofia pelo Programa de Pós-Graduação em Filosofia da Pontifícia Universidade Católica do Rio Grande do Sul (PUCRS, Porto Alegre, RS, Brasil).

\section{Endereço para correspondência}

Alysson Augusto dos Santos Souza

Pontificia Universidade Católica do Rio Grande do Sul Av. Ipiranga, 6.681, Prédio 4, sala 2

Partenon, 97010-082

Porto Alegre, RS, Brasil 